\title{
Comparison of generic and product-specific Life Cycle Assessment databases: application to construction materials used in building LCA studies
}

\author{
Sébastien Lasvaux ${ }^{1,2} \cdot$ Guillaume Habert $^{3} \cdot$ Bruno Peuportier $^{4}$ - Jacques Chevalier ${ }^{1}$
}

Received: 11 December 2014 / Accepted: 14 July 2015 /Published online: 23 September 2015

(C) Springer-Verlag Berlin Heidelberg 2015

\begin{abstract}
Purpose The Life Cycle Assessment (LCA) has been applied in the construction sector since the 1990s and is now more and more embedded in European public policies, e.g., for Environmental Product Declaration regulation or for building labeling schemes. As far as the authors know, these initiatives mainly rely on background impact data of building products provided by different databases' providers. The new productspecific and company-specific EPD data allow having more than one data for describing a building material. But are these new databases really displaying similar LCA results compared to generic databases? Does it depend on which impact category (e.g., global warming, acidification, toxicity) is considered? Methods To answer these research questions, this paper assesses numerical and methodological differences of two existing LCA databases for building LCAs: the
\end{abstract}

Responsible editor: Walter Klöpffer

Electronic supplementary material The online version of this article (doi:10.1007/s11367-015-0938-z) contains supplementary material, which is available to authorized users.

Sébastien Lasvaux

sebastien.lasvaux@gmail.com

1 Environment and Life Cycle Engineering Division, Scientific and Technical Centre for Buildings (CSTB), University Paris-East, 24 Rue Joseph Fourier, 38400 St Martin d'Hères, France

2 Laboratory of Solar Energetics and Building Physics (LESBAT), University of Applied Sciences of Western Switzerland (HES-SO), Avenue des Sports 20, 1401 Yverdon-les-Bains, Switzerland

3 Institute for Construction and Infrastructure Management, Chair of Sustainable Construction, ETH Zurich, 8093 Zurich, Switzerland

4 Centre for Energy and Processes, MINES ParisTech, 5 rue Léon Blum, 91120 Palaiseau, France ecoinvent generic database and one Environmental Product Declaration (EPD) database developed in France. After reviewing the main assumptions of these databases, numerical values of environmental impact are compared for 28 building materials using Life Cycle Impact Assessment (LCIA) indicators of the EN 15804 standard calculated based on cradle-to-gate ecoinvent and EPD Life Cycle Inventories (LCI).

Results and discussion Global results at the database level indicate deviations of different magnitudes depending on the LCIA indicators and the building materials. While indicators correlated to fossil fuel consumption, such as the ADP, the GWP, and the primary energy demand, exhibit a small deviation (approximately $25 \%$ ), other indicators, such as the photochemical ozone formation (POCP), radioactive waste, and ADP elements, are found to be more variable between EPD and generic data (sometimes by more than $100 \%$ ). Three indicators are found to be systematically different between EPD and generic data (i.e., the EPD value being either higher or lower for all materials). Similarly, five building materials show systematic differences for all LCIA indicators. Specific deviations for one indicator and one material are also reported. The application of the two databases on three building LCA case studies (brick, reinforced concrete, and timber frame structures) identifies deviations due to the most influential materials.

Conclusions Current generic and EPD databases can present very different values at the database scale which depend on the type of environmental indicator. For building LCA results, the situation is different as generally speaking a limited number of materials controlled the impacts. Finally, recommendations are presented for each environmental indicator to improve the consistency of the building assessment from generic to product- and country-specific information. 
Keywords Building assessment · Comparison · Construction products $\cdot$ EPD $\cdot$ Generic data $\cdot$ LCA

\section{Introduction}

The environmental impacts of the construction sector have been a major concern since the beginning of the industrial revolution. In 2013, buildings consume $30 \%$ of the world's total energy use and produce $25 \%$ of total $\mathrm{CO}_{2}$ emissions. In addition, the construction sector generates approximately $75 \%$ of the world's total waste. According to Horvath (2004), no other industry in the USA uses more materials by weight than the construction industry. Because of its economic strength and societal importance, construction is also a significant polluter and a target of growing stakeholder scrutiny (Horvath 2004). Similar trends are also found in Europe (EC 2010, 2014).

To evaluate the environmental impacts, a comprehensive environmental assessment tool is needed. Quantitative methodologies have been developed such as the Life Cycle Assessment (LCA) method. LCA is a scientifically based methodology that quantifies the environmental impacts of any product or service over its life cycle (ISO 2006a). It has been applied to the construction sector leading to the development of methodologies and decision-making tools (Peuportier et al. 2011; Lasvaux et al. 2014a; PRESCO 2014; LoRe-LCA 2014). LCA standards were also developed in the European construction sector to further harmonize the calculation rules (AFNOR 2004; CEN 2012a, b).

Over the past 20 years, different generic LCA databases have been developed, such as ecoinvent, ELCD, GaBi, DEAM, and US-LCI. While the LCA approach is being used more and more in the different economic sectors, sectorspecific standards are being developed to calculate the impacts of every product using Product Category Rules (PCR). In the construction sector, such standards aim to provide European or national rules for the assessment of environmental impacts of the production of construction materials sold in each country by different producers (AFNOR 2004; ISO 2006a, b; CEN 2012a). These sector-specific rules are linked to the development of LCA databases adapted to these industrial practices. For instance, these databases use common rules defined in the PCR, which can be a standard such as EN 15804 or NF P 01010 . The databases based on product- and country-specific information are able to take into account process-specific information (Gomès et al. 2013).

In that context, two main categories of LCA databases are found in practice: (1) the generic databases mainly provided by academics and consultancy firms, e.g., ecoinvent centre, PE International, and EC-JRC consisting partly or mainly in generic data; and (2) databases provided by industry that are sector- or product-specific, e.g., Environmental Product
Declaration for building products (INIES 2013), EPD for plastics (PasticsEurope 2014), and EPD for steel (WorldSteel 2014). Generally speaking, generic data are proxy data that can be used in a national context but will not be able to describe environmental impacts of a product sold by a specific building manufacturer (located in the country or abroad), unlike specific EPDs (JRC 2012). In addition, in Europe, EPDs may use comparable PCRs (if appropriate), company-specific individual foreground data, and partly different generic background data (mainly GaBi and ecoinvent, a few probably DEAM).

The level of detail in generic and industry datasets can be very different, as shown in previous studies (Lasvaux et al. 2014a, b; Winkler and Bilitewski 2007). In that way, generic databases may be more complete in terms of elementary flows inventoried and unit processes taken into account. EPD data can be produced by different manufacturers for the "same" building material, allowing the assessment of industrial variability, while in some databases (e.g., ecoinvent database up to version 2) usually only one set of proxy data is provided.

As these two types of data refer to different background assumptions, in this paper we are interested in identifying and understanding whether the use of EPD or generic data for the different building materials leads to substantial differences in each impact category, e.g., $\mathrm{CO}_{2}$, acidification, waste, water, etc., in building LCA studies.

Several studies have already compared LCA databases and tools (Peeredoom et al. 1999; Shelie and Thomas 2006) by sometimes looking at the building sector (Peuportier et al. 2011; Haapio and Viitaniemi 2008; Takano et al. 2014). For example, Peuportier et al. (2011) compared the results provided by eight European building LCA tools. The authors found that the tools do not differ more than $10 \%$ for the $\mathrm{CO}_{2}$ emissions of a single family house (Peuportier et al. 2011). More recently, Takano et al. (2014) analyzed the $\mathrm{CO}_{2}$ values of five generic databases used in building LCA. The authors found that the assessment results are consistent with each other even though they are based on different methodologies.

As reported by these previous studies, the existing building LCA tools use different background generic or industry data. However, no detailed study has been conducted so far in the scientific literature on the impact of using generic or EPD data on the final result of a building LCA study for a broad set of indicators beyond energy and greenhouse gas emissions. EPD data for construction products are relatively new and present potential variability due to the different producers, raw materials supplies, specific energy use, etc.

In this paper, the goal is to assess the deviations between Life Cycle Inventories (LCI) and Life Cycle Impact Assessment (LCIA) values for the commonly used materials in building LCA using the generic ecoinvent version 2 database and the EPD database INIES developed in France as a comprehensive case study. 


\section{Materials and methods}

\subsection{LCI data}

A sample of aggregated LCI data was selected from two existing LCA databases. First, we collected LCI data from the generic ecoinvent version 2.01 database, which is a Swiss database that has been developed over the last 25 years (Frischknecht et al. 2007a, b). Data for materials are presented as cradle-to-gate in the form of unit process data (disaggregated LCA) or as cumulative LCI (aggregated data).

We also collected LCI data from the national EPD database of construction products in France. LCIs are derived from the publicly available documentation report of each EPD stored in the INIES database (INIES 2013). The EPD data from the INIES database is calculated as cradle-to-grave, including cradle-to-gate data based on industry data and gate-to-grave data using scenarios for the transport to the building site, the on-site implementation, the use phase (a service life is defined in the functional unit), and for the end-of-life (EOL) (AFNOR 2004). The INIES database is mainly based on LCI of French industry and energy networks (e.g., specific fuel supply) and on EPD rules that specifically described the calculation rules, e.g., for energy modeling.

Table 1 presents the main assumptions related to the two types of LCIs in terms of data format, cut-off rules, allocation of recycled products, data quality and representativeness for the foreground and background processes, and the number of elementary flows inventoried. These criteria do not pretend to be exhaustive but are assumed to give an overview of the main similitudes or differences of the databases under study.

\subsection{Sample of construction products}

In previous building LCA studies, most of the impacts are driven by a reduced number of construction products. At the same time, not all construction products have LCA data in ecoinvent or an EPD in the INIES databases. Ecoinvent building materials were chosen as a basis for the analysis and associated to available EPDs in INIES. That is to say, the level of details of the building materials was defined based on ecoinvent nomenclature, e.g., for rock wool insulation products, all rock wool EPDs were averaged. Similarly, if EPDs are currently missing, we did not include the ecoinvent material, such as bitumen and wood wool products. Given these hypotheses, 28 main building materials were considered for comparison, as shown in Table 2. Because EPDs cover different commercial references from several building manufacturers, more than one EPD can exist for each building material. For instance, some insulation products have a single manufacturer's EPDs of the different producers that sold their products on the French market. In contrast, the ecoinvent database usually provides only one LCI data for a building product. Table 2 presents the name of the building materials, the corresponding density and the number of data in each database. The Electronic supplementary material presents the corresponding ecoinvent data.

\subsection{Data treatment}

\subsubsection{Harmonization of system boundaries}

First, the system boundaries were harmonized between the two types of LCI data. We broke down the life cycle stages to only keep the cradle-to-gate data of the EPDs. By doing so, we reconstructed an LCI of EPD for only the production stage. No modifications of system boundaries were done on the ecoinvent data as they were already in a cradle-to-gate format (see Fig. 1). In addition, the functional unit was scaled to $1 \mathrm{~kg}$ for each construction product to compare the impact values provided by the two LCA databases on the same basis and to remove the possible differences due to the different densities. All assumptions are presented in detail in Lasvaux (2010).

\subsubsection{Harmonization of LCI nomenclature}

To compare the different data sources, the LCIs need to be harmonized, i.e., to have comparable elementary flows to allow the calculation of the same environmental indicators. Figure 1 presents the harmonization procedure. The comparison is based on the less detailed LCI nomenclature. In this study, we used the reduced LCI proposed in AFNOR (2004) with 168 elementary and reminder flows for both ecoinvent and EPD data using the assumptions presented in Lasvaux (2010) and Lasvaux et al. (2014a, b).

\subsubsection{Choice of Life Cycle Impact Assessment (LCIA) indicators}

The ecoinvent and INIES EPD databases calculate environmental indicators with different assumptions concerning the choice of the LCIA method, the characterized elementary flows, and the value for the characterization factors. Generally speaking, it is important to keep the reported values of all flows in any LCIs to correctly assess the impact and to keep the values of specifically measured emissions in the foreground data. However, in this comparative exercise, as the reporting of ecoinvent and EPD LCI does not have the same level of details, all the impact calculations are based on the reduced LCI. This simplification was however assessed in a previous paper by comparing detailed and reduced LCIs on LCIA calculations (Lasvaux et al. 2014a, b).

In this study, we harmonize these three aspects to remove the variability between the two databases in terms of impact assessment calculations. Table 3 presents the names of the indicators and the number of elementary flows characterized from the reduced LCI. The detailed hypotheses concerning the 
Table 1 Comparison of the main LCA hypotheses between the generic ecoinvent and EPD databases (INIES)

\begin{tabular}{|c|c|c|}
\hline \multirow[t]{2}{*}{ Criteria } & \multicolumn{2}{|l|}{ LCA hypotheses } \\
\hline & Ecoinvent v2 & EPD (INIES, France) \\
\hline General aspects & $\begin{array}{l}\text { Commercial database (fees) providing unit process } \\
\text { raw data, LCI and LCIA values for around } 4000 \\
\text { processes (including building materials) }\end{array}$ & $\begin{array}{l}\text { Free database providing reduced LCI and standardized } \\
\text { LCIA values for around } 2000 \text { EPDs of building } \\
\text { materials and products }\end{array}$ \\
\hline LCA format & $\begin{array}{l}\text { Cradle-to-gate in the form of unit process } \\
\text { (disaggregated data) or as cumulative LCI } \\
\text { (aggregated data) }\end{array}$ & $\begin{array}{l}\text { Cradle-to-grave only in the form of aggregated LCI } \\
\text { (reported in the documentation report) }\end{array}$ \\
\hline Cut-off rules & $\begin{array}{l}\text { No strict quantitative rule followed, infrastructures } \\
\text { always included (e.g., the manufacturing plant) }\end{array}$ & $\begin{array}{l}98 \% \text { in mass of the reference flow including criteria of } \\
\text { environmental relevance, possibility to exclude the } \\
\text { infrastructure of production of the building material }\end{array}$ \\
\hline Allocation of co-products ${ }^{\mathrm{a}}$ & $\begin{array}{l}\text { Partitioning (mass or economic), no substitution } \\
\text { approach }\end{array}$ & Partitioning (mass or economic), no substitution approach \\
\hline Allocation of recycled processes ${ }^{b}$ & $\begin{array}{l}\text { Cut-off method (the impact from the transport to the } \\
\text { recycling plant allocated to the second product), } \\
\text { no substitution approach }\end{array}$ & $\begin{array}{l}\text { Stock method, close to the cut-off approach (the impact } \\
\text { from the recycling plant allocated to the second } \\
\text { product*), no substitution approach }\end{array}$ \\
\hline Primary data/foreground data & $\begin{array}{l}\text { Various sources: literature, industry survey, } \\
\text { industry-based data (e.g., ISOVER for glass } \\
\text { wool), European average data (e.g., for } \\
\text { PlasticsEurope data) }\end{array}$ & $\begin{array}{l}\text { Industry-specific data reported as single manufacturer's } \\
\text { data or group of manufacturers' data }\end{array}$ \\
\hline Secondary data/background data & $\begin{array}{l}\text { Only background data from ecoinvent database } \\
(\sim 4000 \text { linked unit processes })\end{array}$ & $\begin{array}{l}\text { Different possibilities while ensuring consistency with } \\
\text { the EPD standard (depending on the LCA study, } \\
\text { software, data availability): } \\
\text { - based on industry, supplier's data (if available) } \\
\text { - reference LCIs for the main energy carriers (electricity, } \\
\text { natural gas, fuel) and transportation processes (lorry, } \\
\text { boat, rail) from AFNOR (2005) } \\
\text { - Else, background data from available LCA databases } \\
\text { (e.g., DEAM, ELCD, ecoinvent, GaBi) }\end{array}$ \\
\hline $\begin{array}{l}\text { Elementary flows (as a minimum } \\
\text { basis) }\end{array}$ & $\begin{array}{l}\text { 4000 elementary } \\
\quad \text { flows (per sub-category) }\end{array}$ & $\begin{array}{l}\text { 168 elementary and reminder flows (e.g., secondary } \\
\text { resources, recycled waste) based on a recommended } \\
\text { standardized reporting template }\end{array}$ \\
\hline
\end{tabular}

${ }^{\text {a }}$ While the allocation of co-products follows the same general rule derived from ISO 14040, there is no evidence that the rules be similar when looking at a specific building material

${ }^{b}$ For EPDs from INIES, the impacts related to the transport of the recycled waste to the recycling plant is allocated to the first product

calculations of the impact assessment can be found in Lasvaux (2010).

First, six LCIA indicators were considered in line with current standards for EPDs: NF P 01-010 (AFNOR 2004), XP P01-064/CN (AFNOR 2004), and EN 15804+A1 (CEN 2012a). These parameters represent mid-point indicators calculated from resource consumption flows, e.g., the Abiotic Depletion Potential (ADP) indicator as well as the ADP for non-energy resources (ADP elements) following Van Oers et al. (2002) and CEN (2012a, b), and indicators calculated from air emissions, e.g., the 100-year horizon global warming potential (GWP), the acidification potential (AP), the photochemical ozone formation potential (POCP), and the air pollution indicator, which gives the potential toxicity impact calculated by the critical volumes' method.

Second, we calculated indicators describing resource use or waste generation according to EN 15804 (CEN 2012a) and ILCD (JRC 2012). Even if they do not correspond to LCIA indicators, such parameters are useful for interpreting any LCA study or result. These parameters are derived from the LCI and include the cumulative energy demand (CED) using CED factors for the different energy carriers (Frischknecht et al. 2007a, b), or other heating value factors to calculate the so-called primary energy (PE) expressed in net calorific value in EN 15804. In this paper, it was decided not to assess the differences between different primary energy concepts. So all building material energy indicators are either calculated using CED factors or PE factors (using low heating values). A recent paper of Frischknecht et al. (2015) addresses this aspect in more detail. The net fresh water use indicator that sums the water flows (except water from the sea and water for cooling and turbine use), and the radioactive waste and the generated waste (sum of hazardous and non-hazardous) calculated for ecoinvent data from the different original elementary flows "transformation to dump site" using EDIP assumptions for conversion factors in kilograms of waste (Hauschild and Potting 2005). 
Table 2 Type and number of building materials from the ecoinvent v2 and the EPD databases (INIES)

\begin{tabular}{|c|c|c|c|c|}
\hline \multirow[t]{2}{*}{ \# } & \multirow[t]{2}{*}{ Building materials } & \multirow[t]{2}{*}{ Density $\left(\mathrm{kg} / \mathrm{m}^{3}\right)$} & \multicolumn{2}{|c|}{ Number of LCI data used in the database impact values comparison } \\
\hline & & & Ecoinvent v2 & EPDs \\
\hline 1 & Aluminum & 2700 & 1 & 1 \\
\hline 2 & Autoclaved aerated concrete block & 350 & 1 & 5 \\
\hline 3 & Brick block & $600-2200$ & 1 & 4 \\
\hline 4 & Cellulose fiber & 50 & 1 & 5 \\
\hline 5 & Cement mortar & 2000 & 1 & 1 \\
\hline 6 & Concrete, normal (ready mix) & 2380 & 1 & 1 \\
\hline 7 & Concrete block & 910 & 1 & 1 \\
\hline 8 & Copper & 8900 & 1 & 2 \\
\hline 9 & Fiber cement ${ }^{\mathrm{a}}$ & $1700-1900$ & 2 & 7 \\
\hline 10 & Foam glass & $110-120$ & 1 & 1 \\
\hline 11 & Glass wool & $20-220$ & 1 & 88 \\
\hline 12 & Glued laminated timber ${ }^{\mathrm{b}}$ & $420-495$ & 2 & 1 \\
\hline 13 & Gypsum plaster board & $1000-1250$ & 1 & 45 \\
\hline 14 & Medium density fiberboard (MDF) & 720 & 1 & 5 \\
\hline 15 & Oriented strand board (OSB) & 620 & 1 & 1 \\
\hline 16 & Particle board ${ }^{\mathrm{b}}$ & 680 & 2 & 6 \\
\hline 17 & Particle board cement bonded & 1200 & 1 & 5 \\
\hline 18 & Plywood $^{\mathrm{b}}$ & 550 & 2 & 2 \\
\hline 19 & Polystyrene, expandable (EPS) & 30 & 1 & 10 \\
\hline 20 & Polystyrene, extruded (XPS) & 30 & 1 & 1 \\
\hline 21 & Polyurethane ${ }^{\mathrm{c}}$ & 37 & 2 & 6 \\
\hline 22 & PVC & 1295 & 1 & 13 \\
\hline 23 & Rock wool & $20-250$ & 1 & 44 \\
\hline 24 & Roof tile (brick) & $1200-2200$ & 1 & 1 \\
\hline 25 & Sawn timber ${ }^{\mathrm{d}}$ & $460-620$ & 4 & 3 \\
\hline 26 & Steel (construction) & 7850 & 1 & 5 \\
\hline 27 & Steel (reinforcing bars) & 7850 & 1 & 1 \\
\hline 28 & Synthetic rubber & - & 1 & 1 \\
\hline
\end{tabular}

a Ecoinvent data "roof slate" and "corrugated slab" averaged

b Ecoinvent data "indoor use" and "outdoor use" averaged

${ }^{\mathrm{c}}$ Ecoinvent data "polyurethane, rigid foam" and "polyurethane, flexible foam" averaged

dEcoinvent data "hardwood" and "softwood" and data "air dried" and "kiln dried" averaged

\subsection{Statistical analysis at the database level}

The impact values of the cradle-to-gate average EPDs and the ecoinvent data calculated according to the assumptions presented in "LCI data" to "Data treatment" sections are reported in the Electronic supplementary material S2-S4 for a declared unit of $1 \mathrm{~kg}$. The EPDs were arithmetically averaged for each building material based on either a single manufacturer's or a group of manufacturers' EPDs because market shares of each producer are not publicly available in any databases due to anti-trust regulations. For EPDs data, the
Electronic supplementary material S4 also reports the average impact values, the standard deviation (SD), and the relative standard deviation (RSD) calculated as follows:

$\mathrm{RSD}_{m, p}=\frac{\sigma_{m, p}(\mathrm{EPD})}{\mu_{m, p}(\mathrm{EPD})} \times 100$

The RSD identifies the variability of the average impact values per building material and environmental indicator. The impact values of the two databases are then compared using the percentage of relative deviation 
Fig. 1 Harmonization of LCI and system boundary for both generic LCA and EPD data of building products

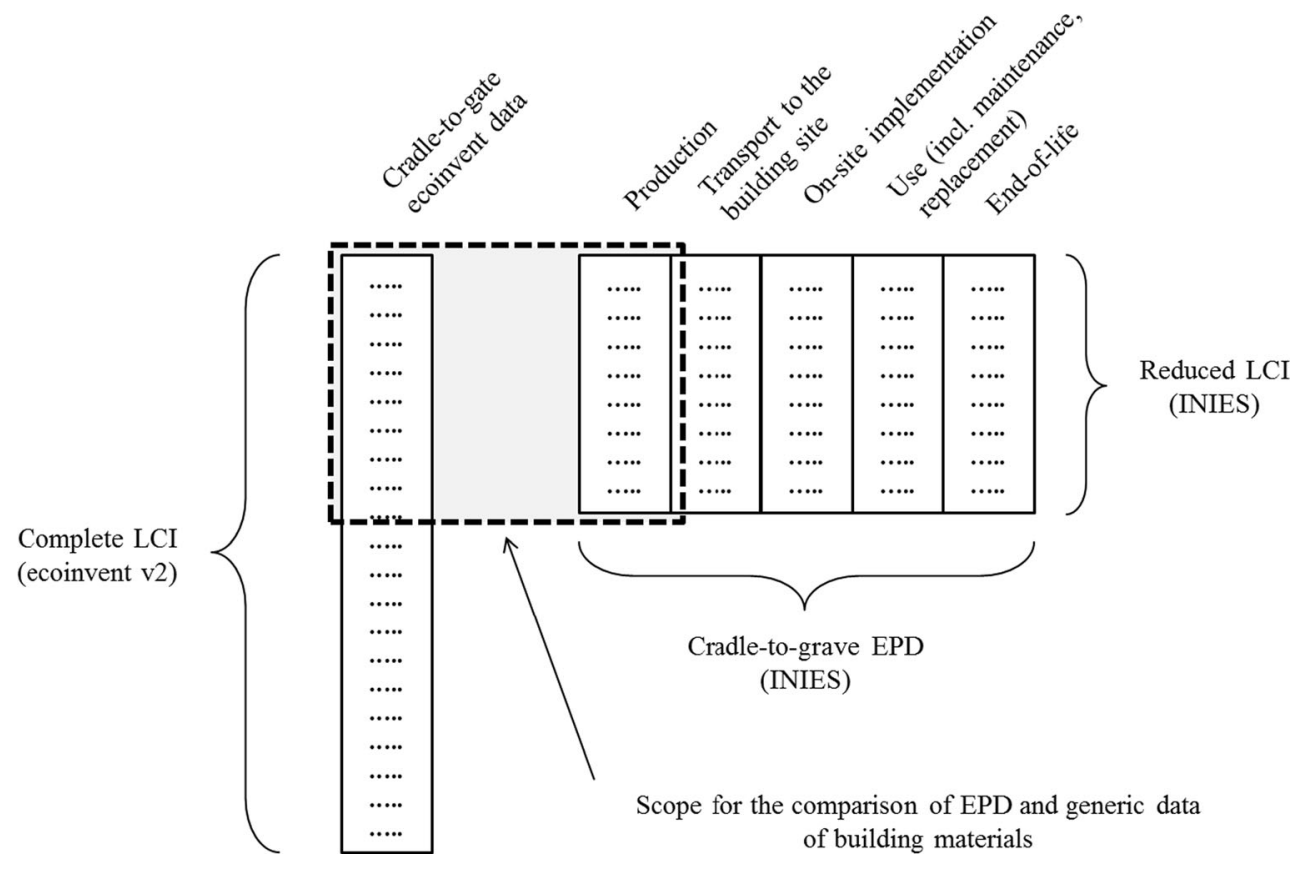

(PRD) calculated with ecoinvent as the reference database (see Eq. 2). In addition, we also calculated the absolute relative deviation between the two databases.

$\overline{P R D}_{m, p}=\frac{\bar{I}_{m, p(\mathrm{EPD})}-I_{m, p}(\text { generic })}{I_{m, p}(\text { generic })} \times 100$

where $\overline{\mathrm{PRD}}_{m, p}$ is the percentage of relative deviation between ecoinvent and EPD data, $\bar{I}_{m, p}$ (EPD) is the average EPD indicator of the impact category $m$ for the product $p$, and $I_{m, p}$ (generic) is the generic data indicator of the impact category $m$ for the product $p$.

For the EPD impact values, we calculated the standard deviation of the PRD for each building material type that had more than one EPD. The Electronic supplementary material S5-S6 presents the mean PRD, its SD, and RSD.

In this study, we identified first priorities of deviations between building material impacts between the generic and EPD databases. The EPDs for the same building product can vary due to different industrial processes, suppliers, and production process efficiency (Gomès et al. 2013). As a result, deviations will in priority be analyzed for impact differences above $\pm 50 \%$ between the average EPD and the generic data.

\subsection{Application to building LCA case studies}

In addition to the analysis of the generic and EPD results at the database level, the deviation should be propagated from the database scale to a building LCA study to identify whether it is a critical problem at the scale of a complete building LCA study. Three building case studies were made with three construction types: a wooden single family house, a multi-residential concrete building, and a brick office building in brick. The same system boundary (production stage) was used, but the different construction materials were weighted according to their mass in the building (see Eq. 3), and the building PRD was then calculated (see Eq. 4). The detailed description of the buildings can be found in COIMBA (2012). The quantity of building materials are presented in the Electronic supplementary material S7.

$$
\begin{gathered}
I_{m, \text { building }}=\sum_{p=1}^{27} I_{m, p} \times m_{p} \\
\overline{P R D}_{m, \text { building }}=\sum_{p=1}^{n} \overline{\operatorname{PRD}}_{m, p} \times c_{m, p} \\
=\sum_{p=1}^{n} \overline{\operatorname{PRD}}_{m, p} \times\left(\frac{I_{m, p} \cdot m_{p}}{\sum_{p=1}^{n} I_{m, p} \cdot m_{p}}\right)
\end{gathered}
$$

where $c_{m, p}$ is the relative contribution of the building material in the building LCA results for the impact category $m, m_{p}$ is the mass of the building material in the

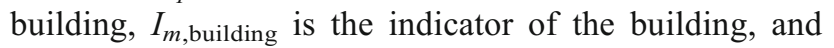
$\overline{\mathrm{PRD}}_{m \text {,building }}$ is the percentage of relative deviation between the building LCA results using either the average EPD or the generic ecoinvent data. 
Table 3 Parameters describing impact assessment, resource use, and waste flows calculated and number of characterized elementary flows from the reduced LCI for ecoinvent v2 and EPDs

\begin{tabular}{|c|c|c|c|}
\hline $\begin{array}{l}\text { Parameters describing impact assessment, resources } \\
\text { use and waste flows }\end{array}$ & Abr. & Unit & $\begin{array}{l}\text { Characterized elementary flows from the } \\
\text { reduced LCI of ecoinvent v2 and EPD }\end{array}$ \\
\hline \multicolumn{4}{|l|}{ Parameters describing environmental impacts } \\
\hline Abiotic depletion potential for fossil resources & ADP fossil & $\mathrm{kg} \mathrm{Sb}$ equiv & 4 \\
\hline Abiotic depletion potential for non-fossil resources & ADP element & $\mathrm{kg} \mathrm{Sb}$ equiv & 44 \\
\hline Acidification potential of soil and water & AP & $\mathrm{kg} \mathrm{SO} \mathrm{S}_{2}$ equiv & 4 \\
\hline Global warming potential & GWP & $\mathrm{kg} \mathrm{CO} 2$ equiv & 3 \\
\hline Photochemical ozone creation potential & POCP & $\mathrm{kg} \mathrm{C}_{2} \mathrm{H}_{4}$ equiv & 5 \\
\hline Air pollution & - & $\mathrm{m}^{3}$ & 39 \\
\hline \multicolumn{4}{|l|}{ Parameters describing resource use } \\
\hline Cumulative Energy Demand & CED & MJ & 7 \\
\hline Net fresh water use & - & $\mathrm{m}^{3}$ & 5 \\
\hline \multicolumn{4}{|l|}{ Parameters describing waste flows } \\
\hline Hazardous and non hazardous waste & - & $\mathrm{kg}$ & 10 \\
\hline Radioactive waste & - & $\mathrm{kg}$ & 2 \\
\hline
\end{tabular}

\section{Results for building material impact deviations at the database level}

\subsection{Global results at the database level}

Table 4 presents the number of building materials' PRD above the threshold of $\pm 50 \%$ for each environmental indicator. We had 28 materials and ten indicators for each material, and we found that $52 \%$ of the values were above this threshold. However, deviations are not the same depending on the indicator and type of material. As an illustration, Fig. 2a presents the global results at the database level of the absolute mean PRD. Deviations are smaller for CED, ADP fossil, and GWP indicators (20-35\%) than for POCP and radioactive waste (300-3600\%). The other indicators fall in between these two groups. The indicators were placed into four groups with an increased mean PRD differences between the two databases:
- Group 1: indicators with a mean PRD between 0 and $30 \%$ (GWP, ADP fossil, CED);

- Group 2: indicators with a mean PRD between 31 and $100 \%$ (AP, net fresh water use);

- Group 3: indicators with a mean PRD between 101 and $250 \%$ (air pollution, waste, ADP element);

- Group 4: indicators with a mean PRD above $250 \%$ (POCP and radioactive waste).

Figure $2 \mathrm{~b}$ reports per indicator the number of materials that have a higher value for a functional unit of $1 \mathrm{~kg}$ either for the average EPD data or for the generic ecoinvent data. A quasisystematic positive deviation was found for two indicators (POCP, radioactive waste), meaning that the average EPD has a higher value than the generic ecoinvent data with the exception of four to five materials. For the other indicators and materials, a similar number of materials had a higher value for the

Table 4 Number of building materials' PRD above the cut-off at $\pm 50 \%$ for each environmental indicator

\begin{tabular}{|c|c|c|c|c|c|c|c|c|c|c|}
\hline & \multicolumn{6}{|c|}{ Impact assessment } & \multicolumn{2}{|c|}{ Resource use } & \multicolumn{2}{|l|}{ Waste flows } \\
\hline & ADP fossil & ADP element & $\mathrm{AP}$ & GWP & POCP & Air pollution & CED & $\begin{array}{l}\text { Net fresh } \\
\text { water use }\end{array}$ & $\begin{array}{l}\text { Radioactive } \\
\text { waste }\end{array}$ & $\begin{array}{l}\text { Hazardous } \\
\text { and non- } \\
\text { hazardous } \\
\text { waste }\end{array}$ \\
\hline $\begin{array}{l}\text { Mean PRD between } \\
\text { EPD and ecoinvent } \\
(\%)\end{array}$ & $\mathrm{kg} \mathrm{Sb}$ equiv & $\mathrm{kg} \mathrm{Sb}$ equiv & $\mathrm{kg} \mathrm{SO}_{2}$ equiv & $\mathrm{kg} \mathrm{CO}_{2}$ equiv & $\mathrm{kg} \mathrm{C}_{2} \mathrm{H}_{4}$ equiv & $\mathrm{m}^{3}$ & MJ & $\mathrm{L}$ & $\mathrm{kg}$ & $\mathrm{kg}$ \\
\hline $\begin{array}{l}\text { Number of building } \\
\text { materials' PRD } \\
\text { below the threshold } \\
\text { at } \pm 50 \%\end{array}$ & 21 & 6 & 13 & 23 & 8 & 10 & 24 & 12 & 4 & 7 \\
\hline
\end{tabular}


Fig. 2 Global results at the database level; a absolute mean PRD (\%) for each indicator, results averaged for the 28 building materials and ranked in increasing order; $\mathbf{b}$ number of building materials with either positive or negative PRD for each indicator; $\mathbf{c}$ mean PRD for building materials with systematic lower impacts for EPD compared to the generic data

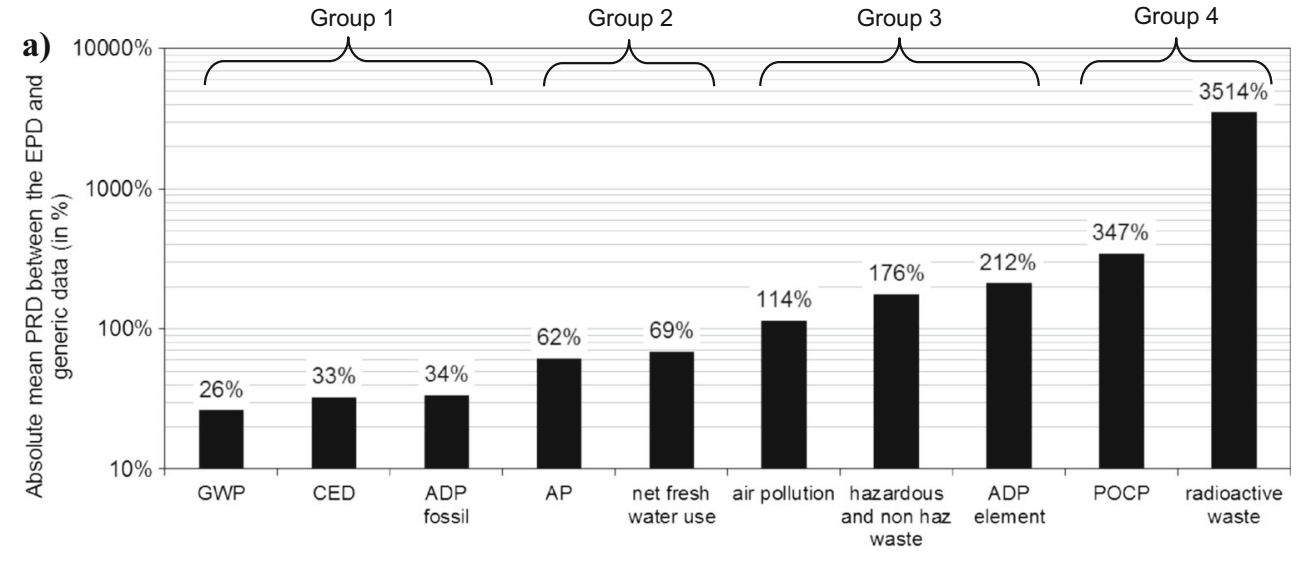

b)

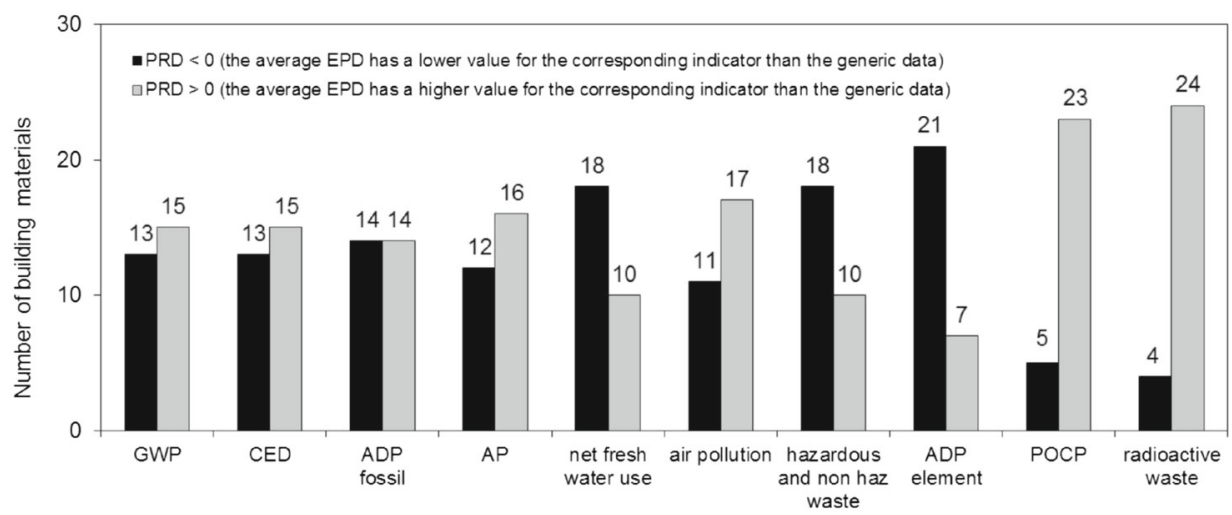

c)

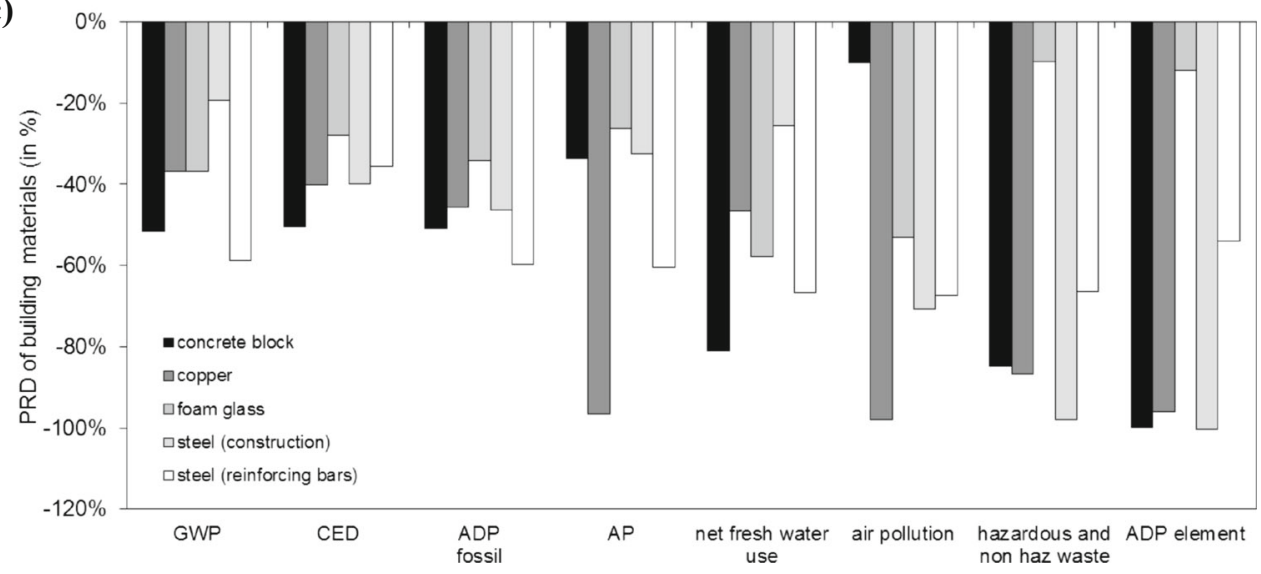

average EPD as well as for the ecoinvent data. This is particularly the case for the GWP, CED, and ADP fossil indicators.

\subsection{Detailed results integrating the variability of EPDs at the database level}

Next to the average PRD values, Fig. 3 presents the standard deviation of the average PRD values between the two databases for each building material. The SD of the PRD values takes into account the standard deviation of the average EPD due to different producers and application types (industrial variability). In Fig. 3, four scatterplots are represented for the four groups of indicators introduced in Fig. 2a. Results show that average PRD mostly fall within the $\pm 50 \%$ differences threshold for CED and GWP indicators (group 1). In addition, by taking into account the variability of EPDs, we also find in Fig. 3 that the PRD for a specific EPD can be above this limit of $50 \%$ (e.g., for PVC products, the standard deviation bar crosses this limit). The same occurs in the other way (average PRD above the limit and standard deviation falling below the limit). These results show the added value of the averaging of EPDs from different producers and application types for the same building material. In some cases, we can have more differences in the environmental impacts of the 


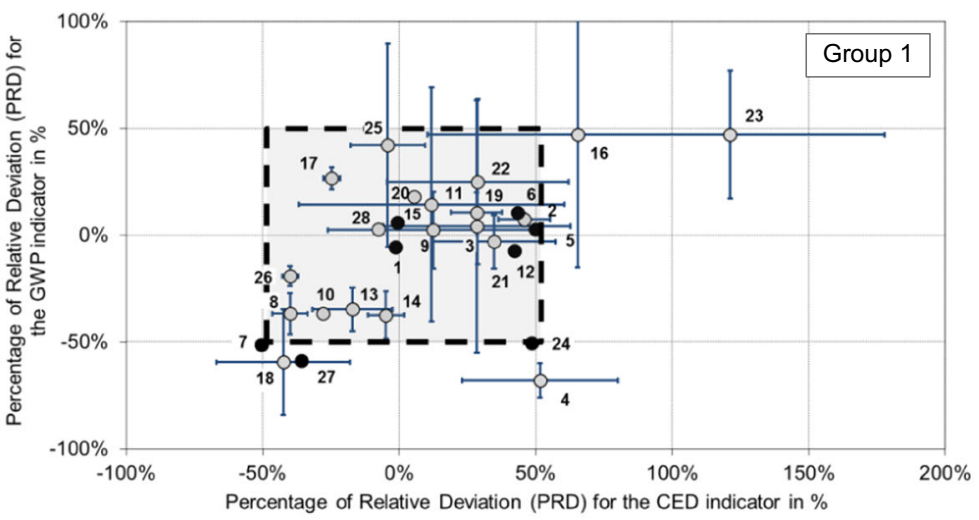

Building materials:

1 - aluminium

2 - autoclaved concrete block

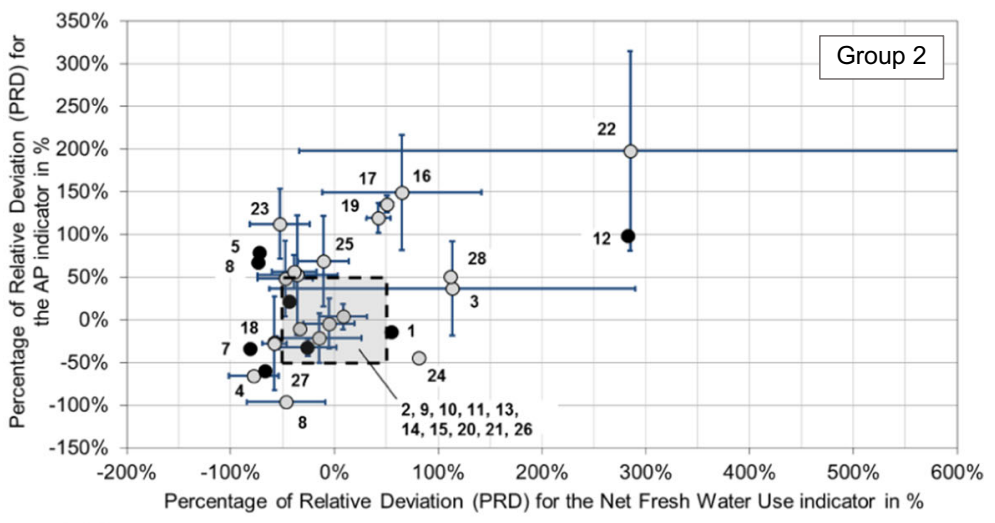

3 - brick block

4 - cellulose fibre

5 - cement mortar

6 - concrete, normal

7 - concrete block

8 - copper

9 - fiber cement

10 - foam glass

11 - glass wool

12 - glued laminated timber

13 - gypsum plaster board

14 - medium density fibreboard (MDF)

15 - oriented strand board (OSB)

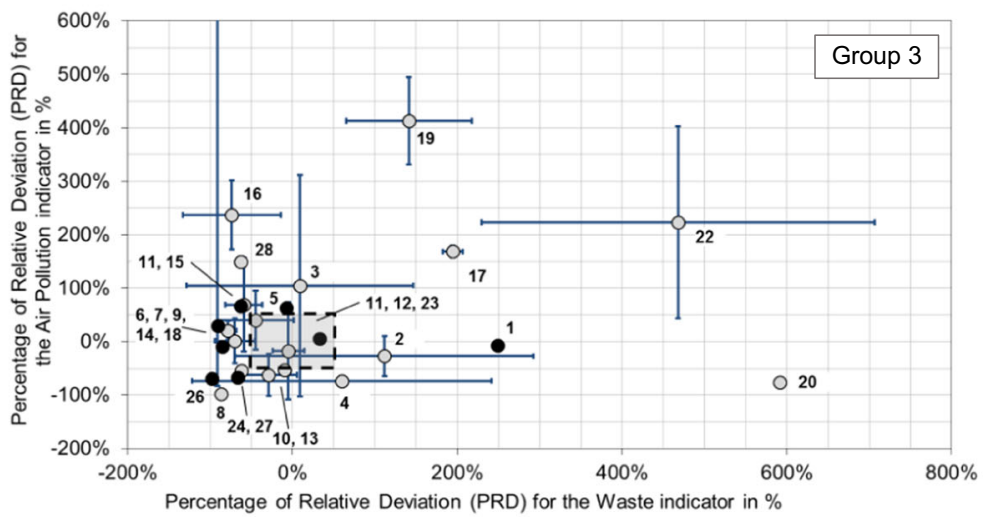

16 - particle board

17 - particle board cement bonded

18 - plywood

19 - polystyrene, expandable

(EPS)

20 - polystyrene, extruded

(XPS)

21 - polyurethane

22 - PVC

23 - rock wool

24 - roof tile (brick)

25 - sawn timber

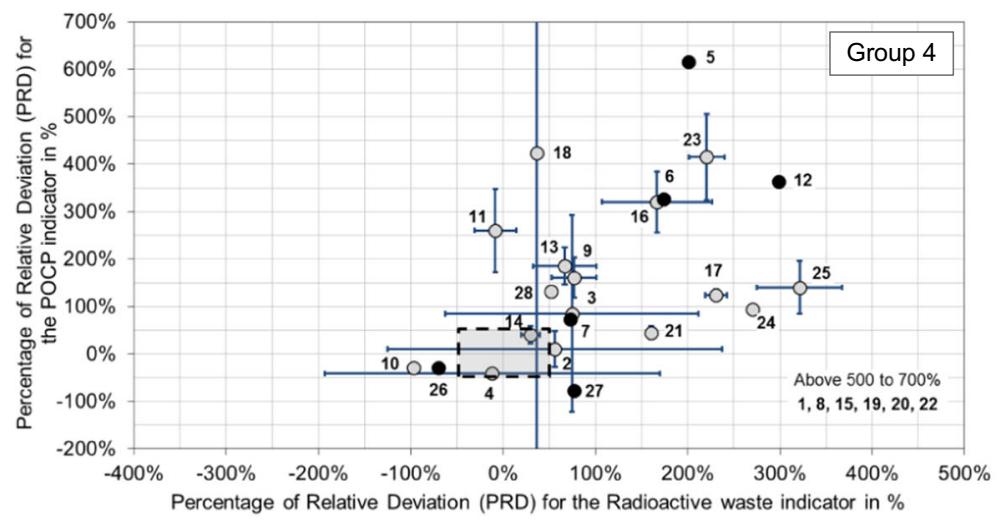

26 - steel (construction)

27 - steel (reinforcing bars)

28 - synthetic rubber

Fig. 3 Percentage of relative deviation (PRD) of each building material's type between EPDs data and generic ecoinvent data for eight indicators of groups 1,2,3, and 4. The black dotted line square represents the threshold at $\pm 50 \%$. Black plain circle represents mean PRD calculated with only one EPD data; gray plain circle represents mean PRD calculated with more than one EPD (the standard deviation around the mean PRD is represented in blue) 
same building material due to different EPDs of different producers with different compositions, recycled rates, and fuel types than between two different generic building materials. Results of Fig. 3 for groups 2, 3, and 4 show that the more we go beyond energy and $\mathrm{CO} 2$-related indicators, the more differences we have between the databases. AP and net fresh water indicators present a higher number of $\mathrm{PRD}$ values within the $50 \%$ limit than air pollution, waste, POCP, and radioactive waste. These results recall what LCA practitioners sometimes face when comparing different LCIA scores (e.g., POCP, AP, toxicity, etc.) of the same material or process from different LCA databases.

\section{Discussion of deviations at the database level}

The PRD results at the database level showed substantial deviations that can be related to different LCA assumptions between generic and EPD data, including data representativeness (e.g., technological, time-related, and geographical), specific production site conditions (e.g., use of green energy), LCA methodology (background data, recycled content, allocation rules), and other aspects (e.g., level of detail of the ecoinvent nomenclature for building materials). Table 5 presents these different aspects related to any building material LCA. In the following sections, we separate out general aspects that potentially explain part of the deviations for all materials and indicators from the specific aspects that explain this study's different cases of deviations (systematic deviation of one indicator or one material or particular deviation for one pair of indicator and material, cf. "Results for building material impact deviations at the database level" section).

\subsection{General aspects}

\subsubsection{Differences in background data for energy processes}

Differences can be found in the energy background data between ecoinvent and EPDs data. In the Product Category
Rules (PCR), recommended LCA data for energy processes are given in the FD P01-015 standard (AFNOR 2006). In this document, the water consumption value differs by a factor of 4 with ecoinvent, while CED and GWP values are much more comparable ( $\pm 10 \%$ ) (Lasvaux 2010). The differences for the water consumption can be explained due to the lack of a common "standardized" approach at least for the databases setup of this study even if the same LCI flows were added up in the ecoinvent and EPD data. As electricity is a recurrent process in EPDs, the deviations found here are to a certain extent propagated in the PRD results.

\subsubsection{Differences in reporting of emission flows}

Differences found in some indicators, e.g., POCP, can be explained by the different information contained in the VOC and NMVOC flows. As VOC and NMVOC are standard emissions in industry and mandatory to report to authorities, they are not more disaggregated in EPDs while in generic databases like ecoinvent, each hydrocarbon and VOC are disaggregated. Depending of the content of the sum of VOC and NMVOC between generic and industry-based data, differences are likely to be found as in this study.

\subsubsection{System boundaries for the production stage: infrastructure and ancillary materials}

Inclusion of infrastructure (e.g., production plant and raw materials extraction infrastructure) is not systematic in EPDs due to the cut-off rules allowed by the PCR (e.g., NF P01-010 or EN 15804+A1). Shelie and Thomas (2006) showed that the omission of a single process in the LCA can significantly affect the final results depending on the impact category under study. As an example, Frischknecht et al. (2007a, b) showed that it is not important for indicators such as GWP, AP, and CED. However, because infrastructures (e.g., buildings) are basically made of concrete and steel, the influence of these processes to the ADP element indicator (depletion of metals) may be not negligible even if the inclusion of infrastructure is still far from being

Table 5 List of data and methodological aspects explaining the deviations between EPDs and generic data

\begin{tabular}{ll}
\hline General aspects & Other aspects \\
\hline System boundaries for the production stage & Level of detail of life cycle inventories' datasets \\
Background data for energy and transport processes & Electricity mix at the production plant \\
Level of details of the building material's nomenclature between databases & Recycled content (for metals) \\
Data representativeness (geographical, time-related, technological) & Technological representativeness of raw materials \\
Allocation of co-products (mass, economic, energy) & Use of green energy certificate \\
& Air emissions regulations/actions at the production plant \\
& Inclusion of secondary energy \\
& Data extrapolation in generic databases
\end{tabular}


accepted or established in all LCA databases. The current discussions on infrastructure in the Product Environmental Footprint guide show that it needs to be included if relevant. While recent studies show it is relevant (Turconi et al. 2014), others show that infrastructure may introduce a high uncertainty into the specific data (Horvath 2006). This explains part of the deviations between ecoinvent and EPDs data for this indicator. As an illustration, the average database PRD between ecoinvent data (without infrastructure) and ecoinvent (with infrastructure) is about $-56 \%$. This value is not far from the one of EPDs (about $-80 \%$ ).

Similarly, for EPDs data, removing the impacts within the production stage is not possible for some ancillary products used for the on-site installation in the building. Generally speaking, the ancillary materials needed for the product to be implemented in the building have a negligible mass (less than $1 \%$ ). Yet, as most of the ancillary materials are made of steel, it results in increasing the ADP elements of some EPDs data (except metals) in contrast to the generic ecoinvent data (e.g., for glued laminated timber, gypsum plaster board, and rock wool products).

\subsubsection{Levels of detail of material nomenclature and EPD variability}

Ecoinvent data are not broken down per uses or producers. In this study, the available EPDs were averaged to match ecoinvent nomenclature, e.g., for glass wool products, an average EPD was calculated. This leads to variability linked to the different impacts depending on producers, processes, and applications in buildings.

\subsection{Specific aspects explaining deviations of one indicator for all materials}

\subsubsection{Level of detail between generic and EPD life cycle inventories}

A quasi-systematic deviation was found for the POCP indicator. EPDs used the hydrocarbons unspecified flows to calculate the POCP. The level of detail between generic and EPD databases can be very different and is the main source of deviations for this indicator (Lasvaux et al. 2014a, b). Similarly, the reduced number of elementary flows in the EPDs LCI does not allow for further calculating LCIA indicators such as biodiversity or noise effects. This is the reason we focus on a limited set of impact categories in this study.

\subsubsection{Electricity mix of the production plants}

Concerning the other problematic indicator, radioactive waste, the systematic deviation is explained by the origin of electricity mix for the production process in the two datasets. The radioactive waste indicator is mostly sensitive to the share of nuclear energy of the electricity in the life cycle of a product. As the ecoinvent data are generally representative of the European or Swiss context, it has a smaller amount of radioactive waste. As an illustration, the amount of radioactive waste in the Swiss electricity mix is approximately $25 \mathrm{mg}$, while it goes up to $36 \mathrm{mg}$ in the French electricity mix (Dones et al. 2007). However, in "Results for building material impact deviations at the database level" section, ecoinvent raw data were not adapted to the French context (assuming $100 \%$ of building materials sold in France are actually produced in France). As an illustration, the Electronic supplementary material S8 presents an update of absolute PRD at the database level. Excluding the deviations for data where no raw data are available in ecoinvent (e.g., PVC and polystyrene) and where no specific national market exists (e.g., copper and aluminum defined in ecoinvent at the European level), the deviation drops from 74 to $24 \%$ on average for the database. This is consistent as all the electricity input of the production process of each building material is now modeled using a French electricity mix. However, we can still find deviations for this indicator, leading us to think that the origin of the electricity input of the production process is not the only parameter to consider when adapting LCA data to another context. As highlighted by Baitz et al. (2012), in practical applications, realistic contextualization will probably always call for more than just a switch of the energy mixes. National specific upstream processes call also for national specific import of resources, production technologies in precursor production, refineries, and extraction operations. At the same time, a strong expertise is needed to prevent the wrong contextualization. For instance, in Switzerland, the update of the glass wool LCA data in the national KBOB database (KBOB 2014) between 2012 and 2014 resulted in a substantial lowering of the GWP impacts mainly due to the change of regional electricity producer (100\% hydropower) (ISOVER 2014). As a result, in the case of construction materials, the switch of national electricity mixes can help in improving the representativeness and reducing the deviations between impact values for radioactive waste, but it cannot be sufficient to ensure a correct representativeness of the data in a national context as other factors interact such as the availability of different electricity producers in the example presented above (see also "Use of green energy certificates for the production plant" and "Geographical and technological representativeness" sections for further information).

\subsection{Specific aspects explaining deviations of all indicators for one material}

\subsubsection{Recycled content for metal building materials}

Results have shown that systematic deviation can occur for some building materials. As an illustration, copper data refers 
to a generic data for ecoinvent and to an average of two EPDs representing tubes and exterior roof coatings. The importation routes and $44 \%$ recycled content in ecoinvent data corresponds to the situation in Germany in 1994 (Classen et al. 2009). On the other hand, analysis of the EPD shows that the data used to model the production of copper is based on a German LCA study for the mining extraction, the refining, and the production of copper as the basis of primary data collected in 2000 (Deutsches Kupfer Institut 2005). These data are also part of the ELCD database and correspond to the European average provided by the industry. The recycled content here is $95 \%$, twice as much as for the ecoinvent data. A simple contribution analysis in SimaPro shows that more than $75 \%$ of the AP impacts are controlled by the primary copper process while only $1 \%$ is driven by the recycled copper. Similar observations can be made for the other indicators (e.g., CED, ADP, net fresh water use, GWP, and waste) that can be explained by the systematic deviations between the two databases for the copper production. The deviation found here also highlights the differences between the background data used in LCA, i.e., ELCD and ecoinvent for the production mix of copper. Similar conclusions are found for the two steel products with a higher recycled content in EPDs of structural steel and reinforcing steel (95-100\%) compared to the ecoinvent assumption (37\%). Interestingly, the EPD's impacts of aluminum are close to the ecoinvent data. Looking at the background information, we notice that the EPD is calculated using background ecoinvent data, including the aluminum production mix data with a same recycled content as in the EPD.

\subsubsection{Use of different raw material quantities}

Use of different raw material quantities can lead to potential differences for all materials. As an illustration, the concrete block in EPD and ecoinvent present different cement contents ( $6 \%$ in the EPD vs. $12 \%$ in ecoinvent). As cement is mostly responsible for the environmental impacts of concrete (Habert et al. 2013), most of the deviation is explained by this database difference. The ready mix concrete data does not present such deviations because the EPD has the same concrete composition as the ecoinvent data.

\subsubsection{Use of green energy certificates for the production plant}

EPDs are likely to be based on specific production plants that may use renewable energies. As an illustration, the foam glass EPD is based on raw data from a US company having the European production plant use $100 \%$ of hydropower from Norway. Interestingly, the ecoinvent data, representing $100 \%$ of the European foam glass market, does not take into account energy certificates and is based on the average European energy mix. This difference is mainly responsible for the systematic deviation found between the two databases for this building material.

\subsection{Other aspects explaining deviations of one indicator and one material}

\subsubsection{Geographical and technological representativeness}

As shown in Fig. 3, the water consumption values between the concrete EPD and generic data are approximately 4 orders of magnitude lower in the EPD data. The analysis of the EPD data shows that it is based on a national LCA study for the ready mix concrete while the ecoinvent data are based on a Swiss LCA study. A simple contribution analysis of ecoinvent data shows that the gravel process is mainly responsible for the water consumption. This deviation can be explained by the background data used to describe the production of the gravel in the two databases. As reported by Künniger et al. (2001), data can vary considerably depending on the mining place and the size of the plant. In France, gravels are mostly extracted from rivers, creating a difference in water consumption from the Swiss context where gravels come from carriers.

Similarly, substantial CED deviation around $+50 \%$ is found for the ready mix concrete based on the same composition (1428 vs. $2105 \mathrm{MJ} / \mathrm{m}^{3}$ ). According to ATILH (2011), the trade union of the cement industry, and Lecouls (personal communication), the reviewer of the LCA study of the French national cement and concrete data, deviations are explained by the secondary fuel shares and the consumption of oil being twice important in the French EPD than in the ecoinvent data. Indeed, the ecoinvent $\mathrm{v} 2$ data does not include in the CED indicator for the secondary energy fuels (Frischknecht et al. 2007a, b). When the secondary energy flows are removed $\left(341 \mathrm{MJ} / \mathrm{m}^{3}\right)$, the CED values are much more comparable: $1428 \mathrm{MJ}$ for ecoinvent and $1754 \mathrm{MJ}$ for the EPD (difference of $\pm 15 \%)$.

\subsubsection{Air emissions reduction measures}

EPDs take into account regulatory aspects including the measures taken by the materials' producers at the production plant (or at the carriers) to reduce air emissions. As an illustration, a deviation of $-62 \%$ was found for the air pollution indicator of the gypsum plaster board products between the two databases. As the air pollution indicator is mainly controlled by particles emitted in the air (Lasvaux et al. 2014a), most of the deviation is linked to the inventory of particles during the extraction of gypsum and at the production plant. According to Lafarge (2010), the gypsum industry has considerably reduced its emissions of particulates in the air over the past several years. As ecoinvent data are based on an older dataset without the emissions reduction, most of the deviation is explained by this aspect and the different temporal representativeness. 


\subsubsection{Data extrapolation in generic databases}

In generic databases, industry data can be missing due to lack of information for a specific process, resulting in creating proxy data, such as for the roof tile brick data. In this study, we found that the ecoinvent data had twice as much impact compared to the EPD for GWP, AP, and ADP fossil indicators. According to ecoinvent assumptions, these data are indeed an extrapolation from the module "brick, at plant". Heating fuel consumption and most emissions have been increased by a factor of 1.5 because of the need to increase frost resistance compared to brick. The electricity consumption has been approximately doubled. Yet, the roof tile brick EPD based on industry data does not present such a difference with the brick data for walls. The extrapolation of generic data might not be relevant in this case.

\section{Application to building LCA case studies}

Low, medium, and high deviations were found between two LCA databases of building materials. The question is now to determine priorities at the building level, once building materials are weighted. Figures 4 and 5 present the PRD of each material and the corresponding contribution percentage for all indicators in one of the building case studies (brick frame building). The building PRD result is reported in the left part of each graph. The results of the other two building case studies are reported in the Electronic supplementary material.

Similar trends are found between the database and the building case studies. Indicators such as CED, GWP, and ADP fossil remain less variable with even shorter deviations in the final building LCA results. The PRD values are between $\pm 20 \%$ for the three building case studies. Indeed, as a building LCA is a weighted sum of different LCA data, positive and negative PRD might in the end be compensated depending on the used materials and quantities. This fact leads to possible building PRD approaching $0 \%$, which happened for the CED indicator. The positive PRD of ready mix concrete was compensated by the negative PRD for MDF particle board as the two materials had a similar relative contribution for CED.

The AP and air pollution indicators were slightly less different from the database study with around $+10 \%$ for the brick and concrete building LCA result and $+40 \%$ for the timber frame.

The two other problematic indicators, POCP and radioactive waste, presented the same trends as for the database scale, i.e., the building PRD is about $+72 \%$ for the POCP and + $140 \%$ for the radioactive waste indicators after the contextualization step. The deviations are, however, much smaller due to the low contribution of some materials with a huge deviation at the database level.
The ADP element values remained very different at the building scale due to the high contribution of metals in buildings for this indicator. As the recycled content is lower in EPDs compared to ecoinvent data (especially for reinforcing steel), the deviation of this material at the database scale is the same at the building scale.

Interestingly, some specific deviations found at the database scale for one indicator and one material are propagated in the final building LCA results, such as for the net fresh water use of the ready mix concrete. Most of the deviation of this indicator at the building scale is explained by both the deviation of concrete datasets at the database level and the high relative importance of concrete for this indicator.

Lastly, the waste indicator is less important in building LCA using EPDs $(-72 \%)$ compared to the same LCA based on generic ecoinvent data. However, waste is an indicator in building LCA mostly controlled by the end-of-life (EOL) stage as opposed to the other indicators in this study that are mostly controlled by the production stage (Lasvaux 2010). If all the building materials are sent to landfill, the amount of direct waste generated at the end of life is about five times the volume of waste at the production stage, leading to a new building PRD of $-13 \%$. As a result, this indicator should not be a problem for cradle-to-grave building LCA applications; the main issue then would be the EOL scenarios that can differ between cradle-to-grave EPDs from different databases.

To summarize the findings of these case studies, Table 6 presents an overview of PRD range for the three buildings including recommendations for each indicator.

\section{Recommendations and conclusions}

A detailed analysis of one generic LCA database and one product-specific EPD database was conducted for a sample of building materials commonly used in building LCA studies.

At the construction materials' database level, these results highlight deviations due to LCA database assumptions or real differences in environmental performances of the selected building materials. In the EPD database, variability is linked to the different manufacturers, production processes, and application types in buildings. Similarly, it can also be due to the possible different interpretations of the product category rules (or the national standard for EPD), e.g., by either specifying the background data or using them "as-such" as shown in a previous study (Modahl et al. 2013).

This study also showed that the indicators linked to fossil fuel consumption are less variable for the sample of construction materials between LCA databases than indicators 

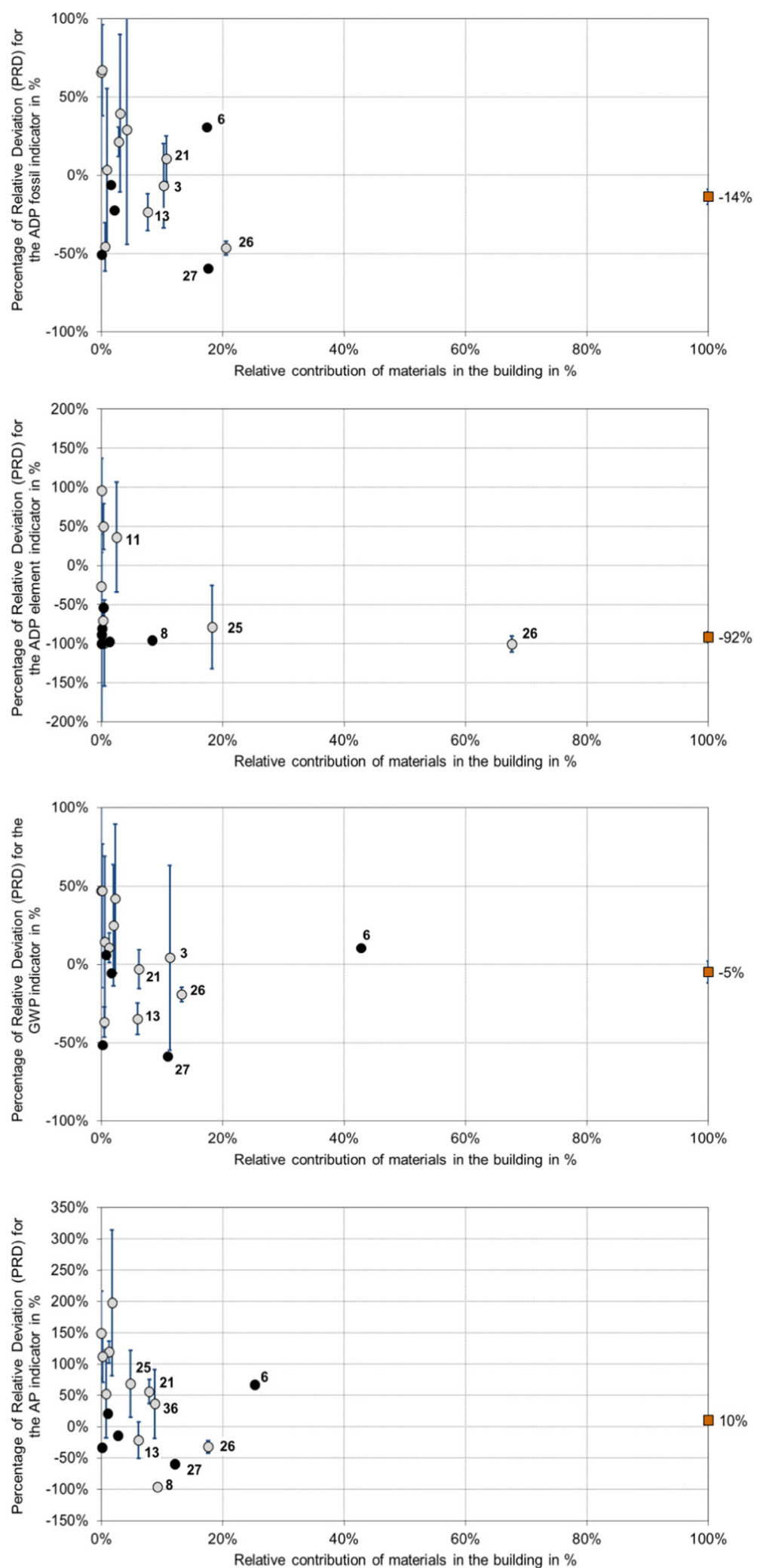

Building materials:

1 - aluminium

2 - autoclaved concrete block

3 - brick block

4 - cellulose fibre

5 - cement mortar

6 - concrete, normal

7 - concrete block

8 - copper

9 - fiber cement

10 - foam glass

11 - glass wool

12 - glued laminated timber

13 - gypsum plaster board

14 - medium density

fibreboard (MDF)

15 - oriented strand board

(OSB)

16 - particle board

17 - particle board cement bonded

18 - plywood

19 - polystyrene, expandable (EPS)

20 - polystyrene, extruded (XPS)

21 - polyurethane

22 - PVC

23 - rock wool

24 - roof tile (brick)

25 - sawn timber

26 - steel (construction)

27 - steel (reinforcing bars)

28 - synthetic rubber
Fig. 4 Percentage of relative deviation (PRD) function of the relative contribution of materials in the building case study; the square point at $100 \%$ represents the PRD of the building LCA value including the variability of EPDs; results presented for the parameters describing impact assessment (ADP fossil, ADP element, AP, GWP). Black plain circle represents mean PRD calculated with only one EPD data; gray plain circle represents mean PRD calculated with more than one EPD (the standard deviation around the mean PRD is represented in blue) 


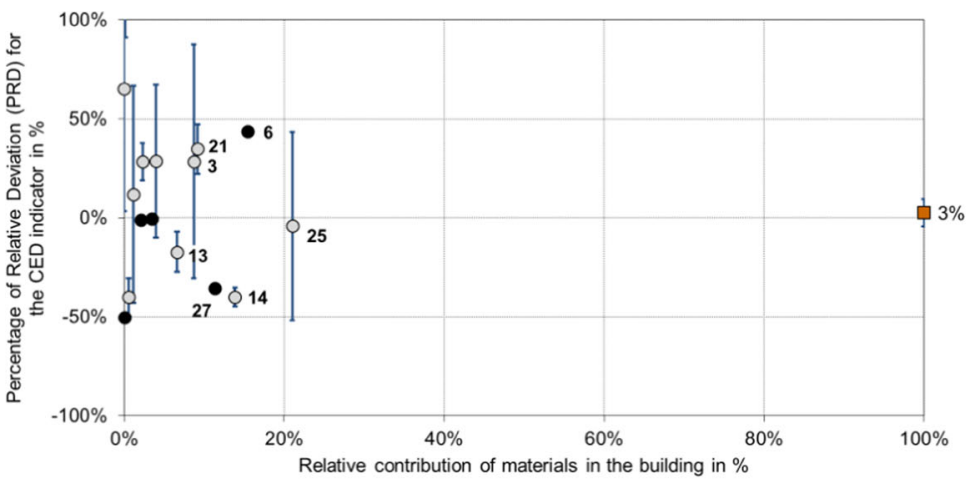

Building materials:

1 - aluminium

2 - autoclaved concrete block

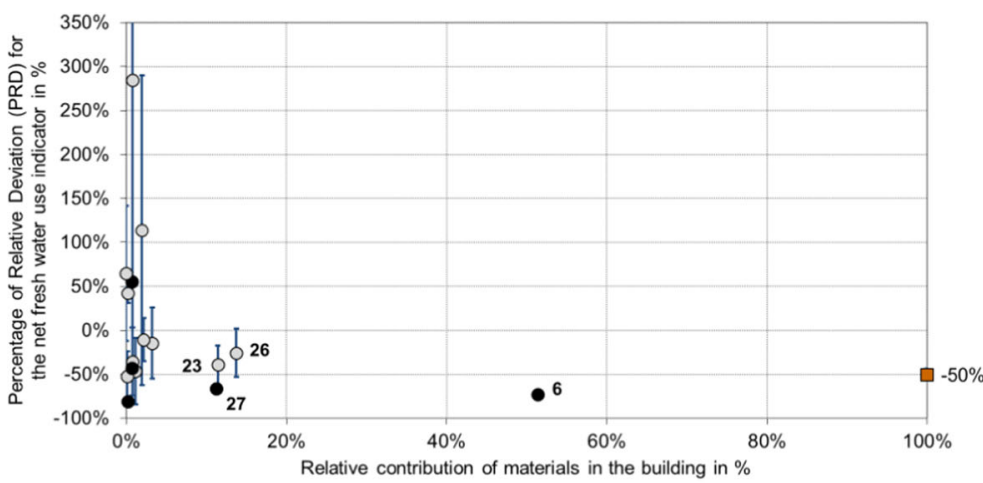

- brick block

4 - cellulose fibre

5 - cement mortar

6 - concrete, normal

7 - concrete block

8 - copper

9 - fiber cement

10 - foam glass

11 - glass wool

12 - glued laminated timber

13 - gypsum plaster board

14 - medium density fibreboard (MDF)

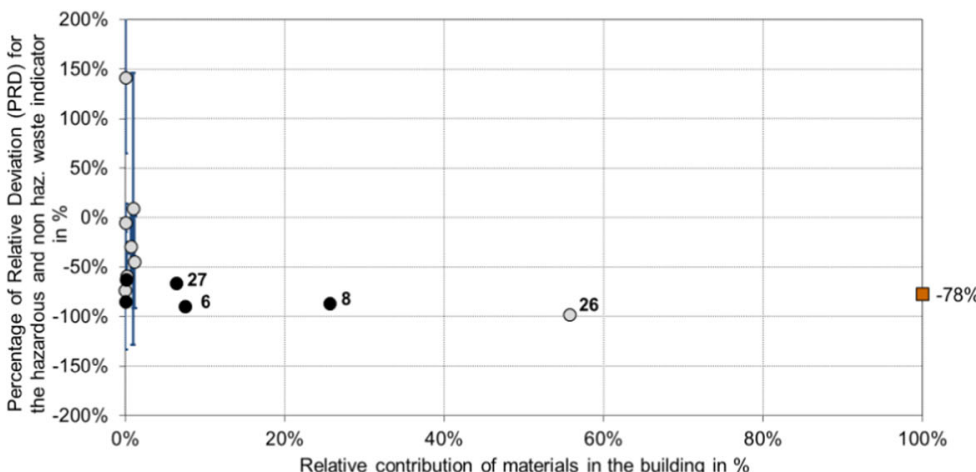

15 - oriented strand board (OSB)

16 - particle board

17 - particle board cement bonded

18 - plywood

19 - polystyrene, expandable (EPS)

20 - polystyrene, extruded (XPS)

21 - polyurethane

22 - PVC

23 - rock wool

24 - roof tile (brick)

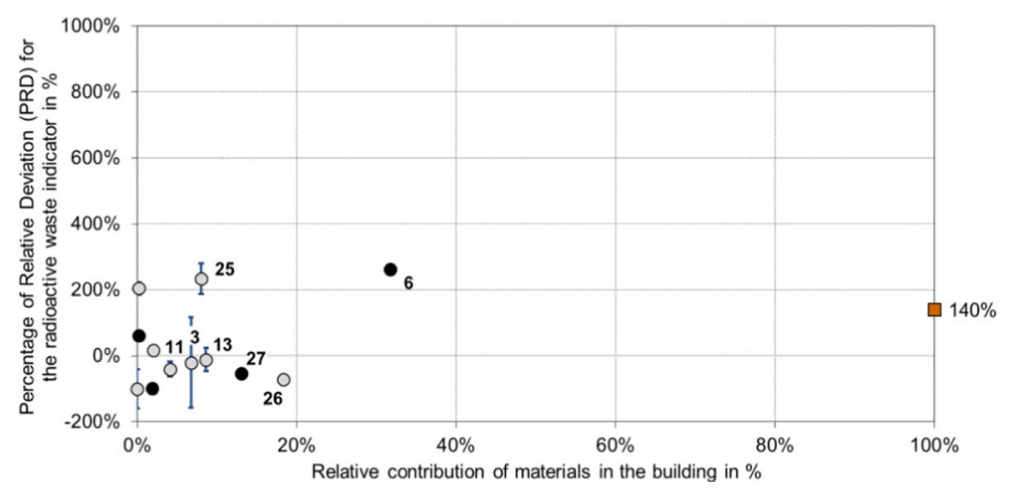

25 - sawn timber

26 - steel (construction)

27 - steel (reinforcing bars)

28 - synthetic rubber

Fig. 5 Percentage of relative deviation (PRD) function of the relative contribution of materials in the building case study; the square point at $100 \%$ represents the PRD of the building LCA value including the variability of EPDs; results presented for the parameters describing resource use and waste flows (CED, net fresh water use, radioactive waste after contextualization, hazardous and non-hazardous waste). Black plain circle represents mean PRD calculated with only one EPD data; gray plain circle represents mean PRD calculated with more than one EPD (the standard deviation around the mean PRD is represented in blue) 


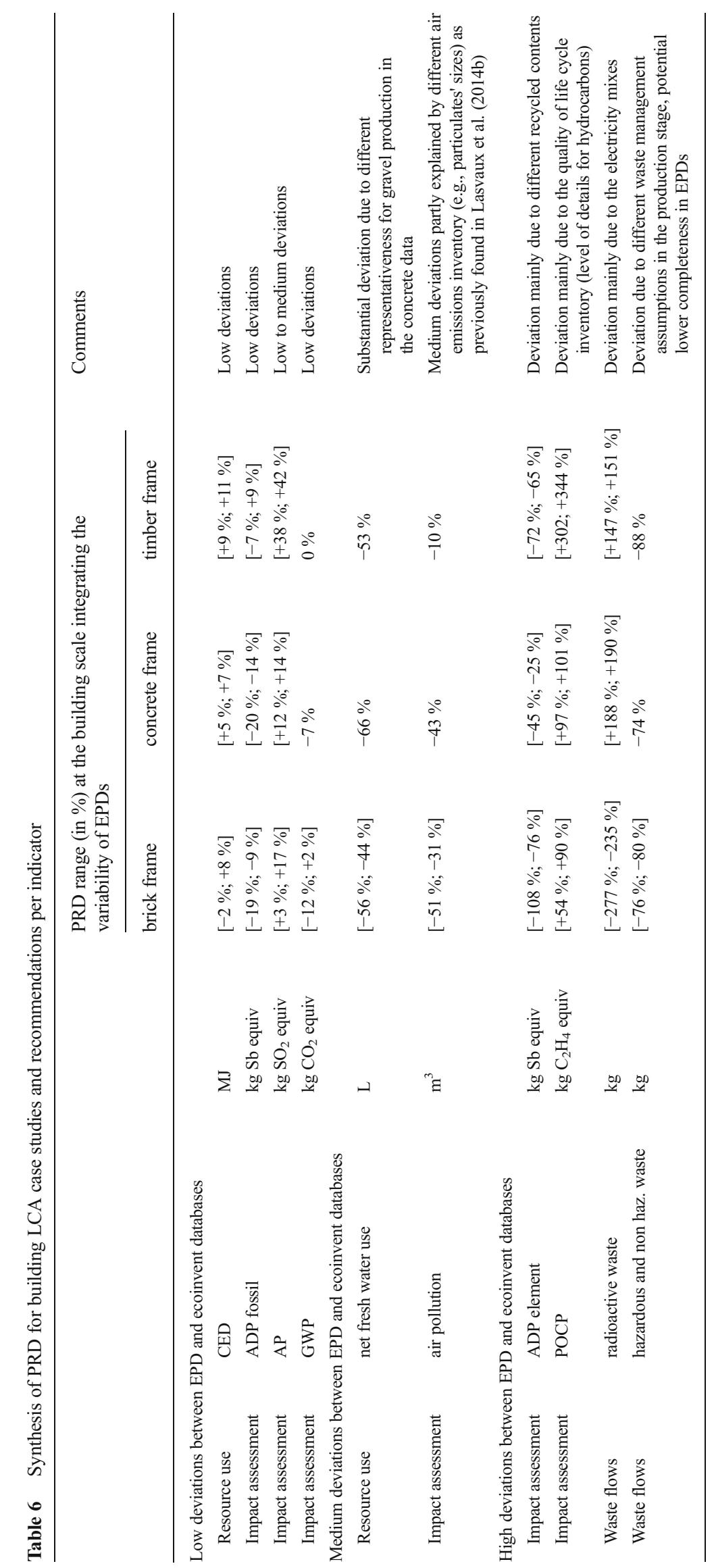


requiring a higher number of elementary flows (e.g., POCP, toxicity,and ecotoxicity indicators). For these indicators, it exists a paradox as a high and detailed number of elementary flows are required for the LCIA while most of these elementary flows are likely to be controlled only by the background system (i.e., whatever the data quality management of foreground data at the manufacturer's plant, it might not change the deviations shown in this study as most of the elementary flows required are not all the time under the responsibility of the manufacturer). A recent study of the influence of ecoinvent and $\mathrm{GaBi}$ background data for product-specific steel products' LCIA is also in line with this interpretation (Lesage et al. 2013).

This finding can contribute to the current discussions about adding additional impact categories (e.g., toxicity and ecotoxicity) in the EN 15804 standards for EPD of construction products in Europe (CEN 2012a). Unless background data are the same among all EPDs, there is a higher risk of major deviation for these indicators calculated using different background data for the same material.

For buildings' LCA studies, results for the brick, concrete, and timber frame buildings confirmed the deviations found at the database scale for the problematic indicators. They also revealed that for indicators under scrutiny by public policies (e.g., CED or GWP), differences in final building LCA results are less than $20 \%$ and sometimes closed to $0 \%$ due to compensations among the materials' PRD. Based on the results presented in "Results for building material impact deviations at the database level" section, discussions, and building LCA case study from "Discussion of deviations at the database level" and "Application to building LCA case studies" sections, the following conclusions can be done:

1. For some indicators, mixing LCA databases, i.e., having EPDs calculated with different background data in the same EPD database, may not be appropriate.

2. For some building materials, the specific processes used by the manufacturers in the national context make data mixing difficult even if these materials do not show a high contribution on the building LCA results.

3. Results for building LCA case studies on the main indicators used in the building sector (i.e., CED and GWP) are relatively comparable between these two databases. They are controlled by materials that usually have a high contribution for one of the studied indicators.

While further studies could be done using larger and more updated datasets (e.g., new average EPDs, single manufacturer's EPDs, or ecoinvent v3 datasets), it would also be relevant to apply the same approach to compare other European LCA databases, such as the other national EPD databases and other generic databases (ELCD and GaBi).

At a time where public policies are more and more based on LCA in France and in Europe, it is crucial to adapt the level of requirements of LCA databases depending on the use in practice. If different background data are used in national EPD databases, a core set of requirements should be clearly stated as, e.g., in CEN/TR 15941 (CEN 2010). However, this may not be enough and more requirements should be added concerning the impact categories if evidence shows that major deviations exist among the available background databases. If we assume (or if the EPD programme requires) that a single and harmonized background database is used for the calculation of generic and product-specific data on construction materials, the remaining variability is then solely related to differences in real environmental performances among manufacturers. These product-specific information on materials can then be used consistently to optimize generic early design building LCA results for a potential larger set of LCIA indicators.

Acknowledgments The authors would like to thank the French National Research Agency (ANR) through the COIMBA and BENEFIS projects for the intial fundings of this study. Sébastien Lasvaux also thank the Bouygues Construction Chair "Sustainable Buildings and Innovation" for its financial support. The authors would like also to gratefully thank one anonymous reviewer for his detailed review that contributes to the improvement of the paper.

\section{References}

AFNOR (2004) Norme NF P 01-010, Qualité environnementale des produits de construction. Agence française de Normalisation. $48 \mathrm{p}$

AFNOR (2006) FD P01-015 Qualité environnementale des produits de construction - Fascicule de données énergie et transport

ATILH (2011) Life cycle inventory of cement production in France (report in French), 28 pages

Baitz M, Albrecht S, Brauner E, Broadbent C, Castellan G, Conrath P, Fava J, Finkbeiner M, Fischer M, Fullana i Palmer P, Krinke S, Leroy C, Loebel O, McKeown P, Mersiowsky I, Möginger B, Pfaadt M, Rebitzer G, Rother E, Ruhland K, Schanssema A, Tikana L (2012) LCA's theory and practice: like ebony and ivory living in perfect harmony? Int J Life Cycle Assess 17(6):1-9

CEN (2010) CEN/TR 15941: Sustainability of construction worksEnvironmental product declarations-Methodology for selection and use of generic data, $16 \mathrm{p}$

CEN (2012a) EN 15804+A1: Sustainability of construction worksEnvironmental product declarations - Core rules for the product category of construction products. European Committee for standardization

CEN (2012b) EN 15978: Sustainability of construction worksAssessment of environmental performance of buildingsCalculation method. European Committee for standardization

Classen M, Althaus H-J, Blaser S, Doka G, Jungbluth N, Tuchschmid M (2009) Life cycle inventories of metals. Final report ecoinvent data v2.1 No.10. Swiss Centre for Life Cycle Inventories, Dübendorf, Switzerland

COIMBA (2012) Knowledge on the environmental impact of buildings, Final report, 244 p. (in French)

Deutsches Kupfer Institut (2005) Life cycle assessment of copper products. Published by Life Cycle Centre, September 2005 
Dones R, Bauer C, Bolliger R, Burger B, Faist Emmenegger M, Frischknecht R, Heck T, Jungbluth N, Röder A (2007) Life cycle inventories of energy systems: results for current systems in Switzerland and other UCTE countries. Final report ecoinvent data v2.0, No. 5. Swiss Centre for Life Cycle Inventories, Dübendorf, $\mathrm{CH}$

EC (2010) Communication from the Commission to the European Parliament, the Council, the European Economic and Social Committee and the Committee of the regions on Resource Efficiency Opportunities in the Building Sector, European Commission, July 2014. Brussels, $10 \mathrm{p}$

European Commission-Joint Research Centre-Institute for Environment and Sustainability (2014) International Reference Life Cycle Data System (ILCD) Handbook - General guide for Life Cycle Assessment-Detailed guidance. First edition March 2010. EUR 24708 EN. Luxembourg. Publications Office of the European Union; 2010

Frischknecht R, Jungbluth N, Althaus H-J, Doka G, Dones R, Heck T, Hellweg S, Hischier R, Nemecek T, Rebitzer G, Spielmann M, Wernet G (2007a) Overview and methodology: Ecoinvent report No. 1. Dübendorf: Swiss Centre for LCI, $68 \mathrm{p}$

Frischknecht R, Althaus H-J, Bauer C, Doka G, Heck T, Jungbluth N, Kellenberger D, Nemecek T (2007b) The environmental relevance of capital goods in life cycle assessments of products and services. Int J Life Cycle Assess 12(1):7-17

Frischknecht R, Wyss F, Büsser Knöpfel S, Lutzkendorf T, Baloutski M (2015) Cumulative energy demand in LCA: the energy harvested approach. Int J Life Cycle Assess 20:957-969

Gomès F, Brière R, Feraille A, Habert G, Lasvaux S, Tessier C (2013) Adaptation of environmental data to national and sectorial context: application for reinforcing steel sold on the French market. Int J Life Cycle Assess 18(5):926-938

Haapio A, Viitaniemi P (2008) A critical review of building environmental assessment tools. Environ Impact Assess Rev 28(7):469-482

Habert G, Denarié E, Šajna A, Rossi P (2013) Lowering the global warming impact of bridge rehabilitations by using ultra high performance fibre reinforced concretes. Cem Concr Compos 38:1-11

Hauschild M, Potting J (2005) Background for spatial differentiation in LCA impact assessment: The EDIP03 methodology. 2005. Institute for Product Development Technical University of Denmark. Environmental Project No. 996, Denmark

Horvath A (2004) Construction materials and the environment. Annu Rev Environ Resour 29:181-204

Horvath A (2006) Environmental assessment of Freight transportation in the U.S. (11 pp). Int J Life Cycle Assess 11(4):229-239

INIES (2013) The French database of reference on the environmental and health characteristics of building products. Available from: www. inies.fr (accessed 20.01.2013)

ISO (2006a) ISO 14040 - Environmental management-Life Cycle Assessment-Framework and principles. International Organization for Standardization, Genève, $31 \mathbf{p}$

ISO (2006b) ISO 14025, Environmental labels and declarations, Type III environmental declarations, Principles and procedures. International Organization for Standardization, Genève, 35 p

ISOVER (2014) Déclaration environnementale de produit selon SN EN 15804 pour la laine de verre non revêtue, liant: biogénique (végétal), $9 \mathrm{p}$

JRC (2012) European Life Cycle Database. European CommissionJoint Research Centre. Available from: http://ca.jrc.ec.europa.eu/ lcainfohub/datasetCategories.vm, (accessed 20.07.2014)

KBOB (2014) Liste de données d'écobilans pour la construction 2009/1: 2014, available online: https://www.kbob.admin.ch/kbob/fr/home/ publikationen/nachhaltiges-bauen.html. Accessed 6 Aug 2015
Künniger T, Werner F, Richter K, (2001) Ökologische Bewertung von Kies, Zement und Beton in der Schweiz.Schweizerische Materialprüfungs- und Forschungsanstalt EMPA, Dübendorf, 2001

Lafarge (2010) Le plâtre et la démarche Haute Qualité Environnementale. Documentation, $8 \mathrm{p}$

Lasvaux S (2010) Study of a simplified model for LCA of buildings (in French). $\mathrm{PhD}$ thesis. MINES ParisTech, $434 \mathrm{p}$

Lasvaux S, Gantner J, Wittstock B, Bazzana M, Schiopu N, Suanders T, Gazulla C, Mundy J-A, Sjöström C, Fullana-i-Palmer P, BarrowWilliams T, Braune A, Anderson J, Lenz K, Takacs Z, Hans J, Chevalier J (2014a) Achieving consistency in life cycle assessmentpractice within the European construction sector: the role of the EeBGuide InfoHub. Int J Life Cycle Assesss 19:1783-1793

Lasvaux S, Schiopu N, Habert G, Chevalier J, Peuportier B (2014b) Influence of simplification of life cycle inventories on the accuracy of impact assessment: application to construction products. J Clean Prod 79:142-151

Lesage P, Boradbent C, Samson R (2013) Choice of background database in constructing cradle-to-gate LCI for public dissemination: case of the worldsteel datasets. LCM2013 International Conference, Gothenburg, August 2013

LoRe-LCA (2014) Low resource consumption buildings and constructions by use of LCA in design and decision-making, European project (FP7), 2014, deliverables available online: http://www.sintef.no/Projectweb/LoRe-LCA/Training/, accessed $25 / 04 / 2014$

Modahl IS, Askham C, Lyng K-A, Skjerve-Nielssen C, Nereng G (2013) Comparison of two versions of an EPD, using generic and specific data for the foreground system, and some methodological implications. Int J Life Cycle Assess 18(1):241-251

PasticsEurope (2014) Environmental Product Declarations, available online: www.plasticseurope.org/plasticssustainability/life-cyclethinking-1746/environmental-product-declarations-epds.aspx (accessed 27.07.2014)

Peeredoom EC, Kleijn R, Lemkowitz S, Lundie S (1999) Influence of inventory datasets on life-cycle assessment results: a case study on PVC. J Ind Ecol 2(3):109e47

Peuportier B, Herfray G, Malmqvist T, Zalabza I, Staller H, Tritthart W, Wetzel C, Szalay Z (2011) Life cycle assessment methodologies in the construction sector: the contribution of the European LORELCA project. Proceedings of the International Conference of Sustainable Buildings, SB11 Helsinki, 18-21 October 2011

PRESCO (2014) Practical recommendations for sustainable construction, European project (FP7), 2011, deliverables available online: www. etn-presco.net/, accessed 25/04/2014

Shelie AM, Thomas LT (2006) Comparison of life-cycle inventory databases a case study using soy bean production. J Ind Ecol 10:133e47

Takano A, Winterb S, Hughesa M, Linkosalmia L (2014) Comparison of life cycle assessment databases: a case study on building assessment. Build Environ 79:20-30

Turconi R, Simonsen C, Byriel I, Astrup T, (2014) Life cycle assessment of the Danish electricity distribution network. Int J Life Cycle Asses 19:100-106

Van Oers L, de Koning A, Guinée JB, Huppes G (2002) Abiotic resource depletion in LCA: improving characterization factors for abiotic resource depletion as recommended in the new Dutch LCA Handbook, Road and Hydraulic Engineering Institute, 75 p

Winkler J, Bilitewski B (2007) Comparative evaluation of life cycle assessment models for solid waste management. Waste Manag 27: 1021-1031

WorldSteel (2014) Life cycle inventory (LCI) data. available online: https://www.worldsteel.org/steel-by-topic/life-cycle-assessment/ about-the-lci.html. Accessed 14 June 2014 